\title{
A EXPANSÃO DA PÓS-GRADUAÇÃO EM CENÁRIOS DE GLOBALIZAÇÃO: RECORTES DA SITUAÇÃO BRASILEIRA*
}

\author{
Antônio Cabral Neto; \\ Alda Maria Duarte Araújo Castro \\ da Universidade Federal do Rio Grande do Norte.
}

\begin{abstract}
Resumo: O artigo analisa o processo de globalização no contexto das inovações tecnológicas e suas repercussões no campo da educação. Discute a centralidade da produção do conhecimento para a competitividade das nações e o papel que a pós-graduação exerce enquanto lócus privilegiado de sua produção. Analisa a expansão desse nível educacional, no Brasil, nas últimas décadas, tomando por base os dados do GeoCapes. Conclui-se que a pósgraduação, nesse contexto de globalização, assume importância fulcral, constituindo-se em um espaço essencial e estratégico de formação de pesquisadores que desempenham papel basal na produção de conhecimentos e no desenvolvimento de novas tecnologias. Nesse contexto, o Brasil vem ampliando o seu quadro de pesquisadores, o que pode ser constatado pela expansão dos cursos, das matrículas e do número de titulados.
\end{abstract}

Palavras-chave: Globalização. Pós-Graduação. Produção do conhecimento.

A pós-graduação no Brasil, nas últimas décadas, vem passando por um processo de substancial expansão em todos os níveis. Neste artigo, parte-se do pressuposto de que, para compreender esse processo de expansão, precisa-se, primeiro, situá-lo no contexto do desenvolvimento do capitalismo, marcado pela intensificação da globalização e pelo consequente aumento de demandas por produção de conhecimento científico, para que os países possam se destacar nesse novo cenário. Para atender a esse

\footnotetext{
* Artigo recebido em 13/10/2012 e aprovado em 05/12/2012.
} 
pressuposto, o texto organiza-se em duas partes. Na primeira, analisa-se a reconfiguração do processo de globalização na conjuntura das inovações tecnológicas e suas repercussões no campo da educação. Discute-se, ainda, a centralidade da produção do conhecimento para a competitividade das nações, evidenciando-se a necessidade de os países investirem em educação, notadamente no nível de pós-graduação, como um dos requisitos para se inserirem, como concorrentes, nesse novo cenário de mudanças. Na segunda parte do artigo, analisa-se a ampliação desse nível educacional no Brasil, ocorrida nessa conjuntura, considerando-se a evolução no número de cursos e de matrículas, tomando como referência as informações contidas na base de dados da Capes (GeoCapes).

\section{MudANÇAS GLOBAIS E NOVAS DEMANDAS PARA PRODUÇÃO DE CONHECIMENTO}

\section{Globalização e regionalização: repercussões para a educação} superior

A globalização caracteriza-se como um fenômeno que vem sendo materializado pelo capitalismo desde a sua origem; é, portanto, um traço imanente ao modo de organização e produção capitalista. Entretanto, ao longo dos tempos, vem se modificando e assumindo novas características, articuladas com as transformações em curso na sociedade capitalista. Nesse sentido, considera-se pertinente a análise de Castells (2001) que diferencia economia mundial de economia global. Para ele, a economia mundial, em que a acumulação do capital avança por todo o mundo, existe, no Ocidente, no mínimo desde o século XVI. Uma economia global é algo diferente:

é uma economia com capacidade de funcionar como uma unidade em tempo real, em escala planetária. Embora o modo capitalista de produção seja caracterizado por sua expansão contínua, sempre tentando superar limites temporais e espaciais, foi apenas no final do século XX que a economia mundial conseguiu tornar-se verdadeiramente global com base na nova infraestrutura, propiciada pelas tecnologias da informação e comunicação. Essa globalidade envolve os principais processos e elementos do sistema econômico. (CASTELLS, 2001, p. 111)

Nessa mesma linha de argumentação, Jameson (2001) preleciona que a globalização, na sua fase atual, postula um novo estágio multinacional do capitalismo, do qual ela é uma característica intrínseca. Para esse autor,

a globalização é um conceito comunicacional que ora mascara, ora transmite significados culturais ou econômicos. Sabemos que hoje há, no mundo 
todo, redes de comunicação mais intrincadas e extensas que são, por um lado, um resultado de inovações notáveis na tecnologia de comunicação, e, por outro, dependem da ampliação tendencial da modernização em todos os países do mundo, ou pelo menos em suas grandes cidades, o que inclui a implementação dessa tecnologia. Mas um conceito de globalização que enfoque apenas as comunicações é essencialmente incompleto. $O$ progresso nas comunicações em nossos dias não é mais relacionado ao "iluminismo", em todas as conotações do termo, mas simplesmente um progresso em novas tecnologias. (JAMESON, 2001, p. 45)

A globalização intensifica a interdependência mundial nos níveis econômico, político, cultural e social, caracterizando, assim, uma crescente transnacionalização dos sistemas de produção, o desenvolvimento dos meios de comunicação e informação, possibilitando a constituição de organizações supranacionais, de âmbito global ou regional, governamental ou não. No entanto, é essencial entender que, no contexto das relações globalizadas, os países de maior poder econômico e político exercem uma hegemonia em todos os campos (econômico, político, cultural, educacional), de modo que os países em desenvolvimento se inserem, de forma subordinada, nessa nova dinâmica.

Em função das novas relações estabelecidas em nível internacional, as organizações multilaterais - como FMI, BIRD, BM, G-7, OTAN - passam a exercer as funções de estruturas mundiais de poder. Ocorre uma tendência do fortalecimento dessas instâncias supranacionais que procuram criar os ordenamentos jurídicos e políticos para orientar o desenvolvimento do capitalismo nessa nova fase. Essas instâncias têm o propósito de reduzir o papel dos estados nacionais e criar uma nova lógica global para direcionar as decisões políticas e econômicas.

Nessa nova dinâmica, o poder econômico tende a ser transferido, cada vez mais, do Estado nacional para centros econômicos transnacionais e deslocalizados, de modo que a ordem econômica não é mais determinada, necessariamente, pelo Estado nacional; ao contrário, os centros econômicos transnacionais passam a ser agentes determinantes desse movimento. Verifica-se, todavia, que os Estados nacionais, mesmo tendo perdido certa autonomia no âmbito da economia globalizada, ainda detêm papel relevante na definição de sua agenda política e econômica.

A globalização, embora vitoriosa em muitos dos seus aspectos, não se concretiza sem enfrentar as contradições que se firmam pelas mediações necessárias entre o global e o local, nos aspectos econômicos, políticos e culturais. Como argumenta Castells, a regulamentação e as políticas governamentais afetam as fronteiras internacionais e a estrutura da economia global. 
Por causa da persistência das nações e governos nacionais e devido ao papel dos governos que usam a concorrência econômica como ferramenta de estratégia política, é provável que fronteiras e separações entre as principais regiões econômicas continuem a existir por muito tempo, estabelecendo uma diferenciação regional da economia global. (CASTELLS, 2001, p. 117)

Para que se consolide um sistema com características de livre comércio, independente da ação de governo, é necessária uma enorme "intervenção desses governos e, de fato, uma concentração de poderes. O livre comércio não se instala naturalmente; precisa ser criado por uma legislação firme e por outros meios de intervenção" (JAMESON, 2001, p. 144).

Embora a economia assuma características globais, ela se expressa, também, na formação de blocos regionais. A ideia de uma economia global regionalizada não representa, em essência, uma contradição conceitual. Como assinala Castells,

Há, de fato, uma economia global porque os agentes econômicos operam em uma rede global de interação que transcende as fronteiras nacionais e geográficas. Mas essa economia é diferenciada pelas políticas, e os governos nacionais desempenham um papel importante nos processos econômicos. No entanto, a unidade da contabilidade econômica é a economia global, pois é nessa escala global que ocorrem atividades estratégicas produtivas e comerciais, bem como acumulação de capital, geração de conhecimentos e gerenciamento da informação. (CASTELLS, 2001, p. 120)

A diferenciação política desse sistema global define, na interpretação do referido autor, os processos econômicos e determina as estratégias dos agentes da concorrência. Nesse sentido, a regionalização interna é um atributo sistemático da economia informacional/global.

É evidente que a forma como os países se inserem nesse movimento está relacionada, dentre outros fatores, com a sua capacidade de investimento em ciência e tecnologia (produção de conhecimento científico e de sua aplicação tecnológica), assim como na formação de pesquisadores/cientistas, o que se realiza, notadamente, em cursos de formação pós-graduada.

A formação de blocos econômicos também repercute no contexto educacional. Uma das primeiras iniciativas de criação de um espaço educacional comum - objetivando inserção dos países no processo de internacionalização e vislumbrando o rentável comércio que poderia advir dos serviços educacionais - foi feita pela Comunidade Europeia, com a criação da Declaração de Bolonha (1999). Essa declaração visava, em essência, estabelecer um Espaço Europeu de Ensino Superior que fosse coerente, compatível, competitivo e atrativo para estudantes europeus e de países 
de outras regiões do mundo. Essa é uma estratégia da globalização focada nos movimentos de capitais, na informação, na tecnologia e que, agora, se expande para a mobilidade de recursos humanos, especialmente de alta qualificação, demarcando uma transferência internacional de conhecimentos e tecnologias.

Essa dinâmica também vem se estendendo entre os países da América Latina, embora cada país, no contexto internacional, se coloque com capacidades diferenciadas para aproveitar as oportunidades que a globalização oferece. É clara a tendência a fazê-lo por meio de blocos de nações, identificadas por interesses comuns, ou individualmente; os países o fazem considerando as suas capacidades e habilidades para se inserirem em blocos de cooperação.

A região tem utilizado, ainda, estratégias e práticas de integração, a exemplo do Mercado Comum do Sul (MERCOSUL) e do Pacto Andino, no âmbito da economia. Segundo Barbalho e Castro (2010), essas experiências motivaram a construção de um espaço regional de educação superior, projeto que se transformou em objeto de políticas públicas, em estratégias de instituições internacionais e regionais. Além disso, as instituições de ensino superior da região viram, nesse processo, a oportunidade de assumir a liderança e promover a cooperação internacional, bem como a possibilidade de atender à demanda de desenvolvimento dos estudantes por novos conhecimentos.

Outra iniciativa que merece destaque para a evolução da educação superior na América Latina foi a Conferência Regional de Educação Superior (CRES), realizada em 2008, em Cartagena de Índias, promovida pela Unesco. A Declaração oriunda dessa conferência apontou, fundamentalmente, a necessidade da cooperação regional, como estratégia para se superar as diferenças na disponibilidade do conhecimento e capacidades profissionais, o saber na ótica do bem-estar coletivo e a criação de competências para a conexão orgânica entre o conhecimento acadêmico, o mundo da produção, o trabalho e a vida. Ademais, identificava no seu Plano de Ação a necessidade da efetivação de uma agenda regional de ciência, tecnologia e inovação para a superação das brechas e para o desenvolvimento sustentável da América Latina e Caribe, assim como a necessidade da construção do Espaço de Encontro Latino-americano e Caribenho de Educação Superior (ENLACES). Essa iniciativa vem se sedimentando na região sob os auspícios de associações e redes universitárias, de instituições de educação superior e de organismos intergovernamentais. 


\section{A centralidade da produção do conhecimento para a competitividade das nações}

A produção do conhecimento, nas últimas décadas, se acelerou significativamente com o rápido avanço da ciência e das novas tecnologias de comunicação. Fainholc (2005) reconhece que, na construção de uma sociedade do conhecimento, a matéria-prima é a informação e o saber e que, nessas circunstâncias, passa-se a requerer dos governos investimentos que favoreçam a sua produção. Nesse sentido, a riqueza das nações já não reside, apenas, no capital físico, mas, sobretudo, na imaginação e na criatividade, considerados os pilares básicos desse tipo de sociedade. Intensificam-se, nesse momento, a valorização e o poder da aprendizagem, da produtividade sociocultural e a sua aplicação em novas tecnologias, o que demanda uma boa capacidade instalada de pesquisa e a formação de recursos humanos de alta qualificação; nesse aspecto, a pós-graduação se sobressai como espaço privilegiado.

O processo de globalização impõe, portanto, a exigência de graus mais elevados de qualificação e de flexibilização da formação do trabalhador em todos os níveis de atuação. Os governos passaram a considerar que em face da crescente circulação de capitais, bens e ideias da nova divisão internacional do trabalho - a educação deveria ser entendida como determinante do desenvolvimento econômico e político das nações. Com o intuito de adequar o campo educacional às novas demandas contextuais, decorrentes do processo de reestruturação do capitalismo, se processa mundialmente, no final do século XX e no início do século XXI, uma série de reformas nos sistemas de ensino. Dentro dessa lógica, a ampliação da educação superior, notadamente a pós-graduada, apresenta-se como lócus privilegiado de formação e produção da pesquisa e do conhecimento, dimensões necessárias para que os países possam competir em um mercado global.

Segundo Mello,

Os desafios históricos, no alvorecer do terceiro milênio, impõem a todos os povos e nações a constituição de uma vigorosa e diversificada rede de inteligência e uma potente capacidade investigadora, em todas as áreas do conhecimento - com a universidade em seu epicentro - como condição sine qua non para toda e qualquer pretensão de salto civilizatório e ao exercício da soberania. (MELLO, 2011, p. 53)

Nessa mesma linha de argumentação, Castells (2001) assinala que, na atual dinâmica produtiva, o conhecimento ocupou o lugar de matéria-prima, 
reformatando-se, desde então, o novo panorama global das desigualdades, agora, medida pelas diferenças cognitivas. Baseado em posicionamentos desse tipo, delineia-se um consenso de que, no âmbito da economia globalizada, a produção de uma força de trabalho educada segundo padrões internacionais é necessária para se aumentar a vantagem competitiva das nações. A concretização dessa dinâmica social requer, por sua vez, a aplicação e a produção de conhecimentos e de informações cuja base científica assume uma crescente importância.

Como explica Carnoy,

Não se trata de um fenômeno de todo novo, porque os conhecimentos nunca deixaram de ser um fator de primeira ordem na organização e no fomento do desenvolvimento econômico. Porém à medida que aumenta a complexidade das economias, o consumo se diversifica, a competência se transforma em conhecimentos e a informação se reveste de uma função cada vez mais importante para os processos de produção e execução. (CARNOY, 1995, p. 127)

Argumenta-se, em esfera mundial, que a economia do século XXI será aquela fundamentada no conhecimento complexo e na sua aplicação criativa. Dessa base, dependerá a maior ou menor lucratividade dos empreendimentos e a competitividade das economias internacionais, nacionais e regionais. Para Mello (2011), o crescimento e a afirmação dos diferentes países na economia global, de forma competitiva e interdependente, dependem da sua capacidade tecnológica, da articulação adequada entre ciências, tecnologia, gestão e produção, sem esquecer os recursos humanos e qualificados em quantidade suficiente em todos os setores estratégicos.

Essa afirmação, referendada por estudiosos da temática, tem contribuído para disseminar a ideia de que a educação - em especial, a educação universitária e pós-graduada - assume um papel estratégico na cadeia do desenvolvimento dos países. Isso porque esse nível educacional desempenha função preponderante na produção do conhecimento científico, que se torna, na atualidade, essencial para o desenvolvimento da capacidade competitiva de uma nação.

Nesse cenário, Carnoy (2002) assinala que são atribuídos, de forma crescente, créditos ao ensino superior, em decorrência das novas orientações da produção econômica, voltada para produtos e procedimentos que exigem um maior volume de conhecimento. Portanto, no contexto da globalização da economia, são colocados novos desafios e novas demandas para a área da educação superior. Um sistema educacional bem estruturado e trabalhadores mais qualificados podem contribuir para atrair capitais de financiamento globalizado que desempenham um destacado papel na economia mundial. 
É nesse contexto que as instituições de ensino superior, de maneira especial a pós-graduação, constituem-se em um espaço de construção e de acesso ao conhecimento avançado, implicando, pois, um instrumento para promoção da cultura, da geração de novos conhecimentos e de atualização permanente. Barbalho e Castro (2010) entendem que a centralidade da educação assume, atualmente, maior importância devido à valorização crescente da inovação e do conhecimento no processo econômico. Este, facilitado pela globalização, concorre para que as sociedades se tornem cada vez mais subordinadas e a sua competitividade externa fique condicionada à incorporação do conhecimento ao sistema produtivo. Essa lógica tem levado a um atrelamento sem igual da pesquisa aos critérios mercadológicos, e o conhecimento passa a ser força produtiva, voltada à valorização do valor no contexto da sociedade capitalista.

Segundo Jantisch (2010), a pesquisa deve ir além desse objetivo e procurar contribuir para a emancipação humana. Entre outros fatores, ele propõe: que a universidade pública seja o ethos privilegiado da pesquisa para além da valorização do capital, espaço em que essa possa ser realizada universalmente para além dos critérios mercadológicos; a defesa de uma regulação estatal pública para além da mercadorização da pesquisa em qualquer espaço universitário; e defesa da universidade enquanto lócus autônomo, isso é, sem tutela de qualquer ordem.

EXPANSÃO DA PÓS-GRADUAÇÃO NO BRASIL: CAMINHOS TRAÇADOS E PERCORRIDOS

Notas sobre a pós-graduação no Brasil

Com a intensificação do processo de industrialização a partir da década de 1930, a necessidade de incrementar o desenvolvimento econômico do país exigiu a inserção da ciência com seus métodos de pesquisas na educação de nível superior, originando, assim, o imperativo da escola pós-graduada no Brasil. Segundo Anísio Teixeira, "A escola pós-graduada de pesquisa e estudos avançados é que teria de preencher a função de preparo dos quadros superiores de cientistas de ciências humanas, físicas e naturais, e das respectivas tecnologias [...]" (TEIXEIRA, 2005, p. 201). Essa escola deveria ser o centro da formação do professor de ensino superior e dos pesquisadores e cientistas humanos, sociais e físicos de todo o país ( $p$. 202-203). Na década de 1960, Anísio Teixeira já alertava para a necessidade de que o Brasil precisava desenvolver um ensino superior completo, que trabalhasse o ensino aliado à pesquisa e à formação docente para o melhor desenvolvimento socioeconômico da nação. No seu entender, o país não 
poderia caminhar, apenas, para universidades de pesquisa, mas também para "multiversidades", isso é, "a universidade industrializada, integrada na sociedade, no seu desenvolvimento global" (TEIXEIRA, 2005, p. 197).

Embora já existisse no país a consciência da necessidade de investimentos na formação pós-graduada, constata-se que, apenas em dezembro de 1965, o então Conselho Federal de Educação aprova o Parecer n. 977. O Parecer Sucupira, como ficou conhecido, reconhece as experiências brasileiras de pós-graduação como um novo segmento de ensino e traça o primeiro formato institucional básico, diferenciado em dois níveis: o mestrado e o doutorado. A importância da pós-graduação, no período da ditadura militar brasileira (1964-1985), se justificou pela premência do desenvolvimento econômico do país, tendo em vista atender às novas demandas decorrentes do avanço do processo de modernização da sociedade. Segundo Oliven (2002), as universidades públicas foram escolhidas para atingir esse fim. Nelas, principalmente nas maiores e mais tradicionais, foram criados cursos de mestrado e, mais tarde, de doutorado.

A criação da pós-graduação veio atender às demandas do momento histórico, político-econômico, pelo qual atravessava o país; dentre elas, a necessidade do crescimento industrial que precisaria formar mão de obra qualificada para o desenvolvimento de novas tecnologias para a indústria e atender à pretensão dos estudantes que desejariam completar sua formação de pesquisador.

No processo de sistematização da pós-graduação brasileira, merece destaque a participação da Coordenação de Aperfeiçoamento de Pessoal de Nível Superior (Capes), criada em 1951, tendo sido instituída, como fundação, em 1992. É uma agência de fomento da pós-graduação que subsidia o MEC na formação de recursos humanos altamente qualificados para a docência em grau superior, na pesquisa e no atendimento à demanda por profissionais dos setores públicos e privados.

Entre as suas funções, podem ser elencadas: a elaboração da proposta do Plano Nacional de Pós-Graduação, o acompanhamento, a coordenação e a sua respectiva execução; a elaboração de planos de atuação setoriais ou regionais; a promoção de estudos e avaliações do desenvolvimento científico e tecnológico nacional; a manutenção do intercâmbio e o contato com outros órgãos da administração pública, ou entidades privadas nacionais e internacionais. Em 1965, com a aprovação do Parecer n. 977/1965, a Capes ganha nova regulação, novas atribuições e meios orçamentários para intervir, de maneira mais efetiva, na qualificação dos profissionais de pós-graduação brasileiros, em universidades públicas (BRASIL, 2010). É com esse respaldo 
que a Capes passa a elaborar, a partir do ano de 1975, os Planos Nacionais de Pós-Graduação (PNPGs), que vão orientar as atividades desse segmento do ensino superior brasileiro, bem como avaliá-lo.

O I Plano Nacional da Pós-Graduação (PNPG) foi elaborado para o período 1975/1979; estabelecia, claramente, a integração da pós-graduação às políticas sociais e econômicas do país e, nesse sentido, passou a se constituir em um componente do planejamento estatal. Vale salientar que os primeiros planos foram elaborados durante a ditadura militar brasileira (1964-1985) e que, por isso mesmo, eles vinham atender ao projeto de modernização do país, idealizado pelos militares que tinham a ideia de que a educação era a força propulsora para que o país se modernizasse. Sendo assim, a educação, em todos os seus níveis, inclusive a pós-graduação, adquire valor de capital humano, pois seria a responsável pela formação qualificada de que necessitava o desenvolvimento do país.

OI PNPG (1975-1979)"estabeleceu como prioridade a capacitação de docentes para instituições de educação superior e a integração das atividades de pós-graduação dentro do próprio sistema universitário" (MANCEBO, 2008 , p. 174). Esse plano trouxe, como principal objetivo, a formação de docentes em nível superior, tendo em vista minimizar as lacunas do quadro docente das instituições desse nível, considerando que, antes, isso só poderia ser feito em instituições estrangeiras, o que dificultava e restringia a formação. Nesse sentido, a concessão de bolsas de estudo a professores de universidades ganhou, a partir de então, maior amplitude ante a necessidade de institucionalizar a pós-graduação, integrando-a ao sistema universitário, e de enfrentar o desafio de corrigir os desequilíbrios entre as diversas áreas do conhecimento e entre as regiões do país.

O II PNPG (1982-1985) tratava da qualidade do ensino superior e da pós-graduação, baseada no princípio da "eficiência e na confiabilidade dos sistemas de informação e avaliação do desempenho dos programas de pós-graduação". Essas exigências fizeram surgir a necessidade de regulação e avaliação desse nível de ensino, passando a ser essa uma das funções principais da Capes. No II PNPG, já havia uma discussão inicial sobre a premência da adequação do sistema de pós-graduação brasileiro ao atual contexto de comunicação e informação, em prol do melhor desenvolvimento do setor produtivo nacional, por meio do desdobramento da ciência e da tecnologia.

O III PNPG (1986-1989) trouxe como inovação a "institucionalização da pesquisa como elemento indissociável da pós-graduação e sua integração no sistema nacional de ciência e tecnologia" (MANCEBO, 2008, p. 174). Tal plano favoreceu, acima de tudo, a produção do conhecimento para promover 
o desenvolvimento nacional, ou seja, a criação de uma identidade nacional sólida. Para tanto, foi preciso privilegiar a formação docente bem como qualificar o sistema de pós-graduação do país, institucionalizando a pósgraduação como segmento público, promovido, necessariamente, por meio da prática da pesquisa em instituições universitárias.

O IV PNPG (1998-2002) foi o primeiro da década de 1990, quando o neoliberalismo se propagava fortemente nas políticas sociais brasileiras. Apesar de ter sido o primeiro a ser "discutido" com a comunidade acadêmica, em 1996, por meio da divulgação, pela Capes, de um documento intitulado "Discussão da Pós-Graduação Brasileira", não contribuiu, de forma significativa, para mudar o patamar da pós-graduação nacional. Segundo Mancebo (2008), o documento que "consolida" o IV PNPG, em 1998, passa despercebido ou esquecido pelos próprios participantes do processo. Concordando com esse posicionamento, Santos (2009, p. 37) afirma que esse plano não passou de um projeto, pois "uma série de circunstâncias, envolvendo restrições orçamentárias e falta de articulação entre as agências de fomento nacional, impediram que o documento final se concretizasse em um efetivo Plano Nacional de Pós-Graduação".

O V PNPG (2005-2010), afinado com as discussões do processo de globalização, incorpora o princípio de que o sistema educacional é fator estratégico no processo de desenvolvimento socioeconômico e cultural da sociedade brasileira. Ele representa uma referência institucional indispensável à formação de recursos humanos altamente qualificados e ao fortalecimento do potencial científico-tecnológico nacional. Segundo o PNPG (BRASIL, 2004), cabe à pós-graduação a tarefa de produzir os profissionais aptos a atuar nos diferentes setores da sociedade e capazes de contribuir, a partir da formação recebida, para o processo de modernização do país. Na avaliação de Mancebo (2008, p. 180), o V PNPG destaca a importância da relação da área acadêmica com o setor produtivo do país; nele, há uma forte ideia de formar profissionais para serem absorvidos pela indústria e criar condições para o surgimento de novas empresas brasileiras a partir do conhecimento gerado na pós-graduação. Como princípios que devem nortear o desenvolvimento da pós-graduação, no período de 1995-2010, o V PNPG estabelece: o estímulo à mobilização permanente da comunidade acadêmica nacional; o incentivo a um processo contínuo de integração com a comunidade científica internacional, pela Capes e CNPq (Conselho Nacional de Desenvolvimento Científico e Tecnológico); a preservação e o aprimoramento das conquistas realizadas pelo sistema nacional de pós-graduação; e o aumento do número de pós-graduandos, do sistema de ciência e tecnologia e do setor empresarial. 
O VI PNPG (2011-2020) evidencia uma preocupação em favorecer a integração do ensino de pós-graduação com o setor empresarial e a sociedade. Em relação ao plano anterior, a sua principal novidade é a adoção de uma visão sistêmica em seus diagnósticos, o que deverá dar origem a um conjunto de programas e ações de governo em termos de políticas públicas. OVI PNPG está organizado em cinco eixos: a) a expansão do Sistema Nacional de Pós-Graduação (SNPG); a qualidade, a quebra da endogenia e a atenção à relação das assimetrias; b) a criação de uma nova Agenda Nacional de Pesquisa e sua associação com a pós-graduação; c) o aperfeiçoamento da avaliação e sua expansão para outros segmentos do Sistema de Ciência, Tecnologia e Informação; d) a multi e a interdisciplinaridade entre as principais características da pós-graduação e importantes temas de pesquisa; e) apoio à educação básica e a outros níveis e modalidades de ensino, especialmente o ensino médio.

Percebe-se que há uma continuidade da ideia de indução estratégica contida no plano anterior e, nesse sentido, um dos eixos do novo plano será a organização de uma Agenda Nacional de Pesquisa, abrangendo temas de acordo com sua relevância para o país e as oportunidades que se avizinham. O combate às assimetrias é outro tema central, cuja complexidade irá exigir a ação sinérgica de vários órgãos de governo envolvidos e a ênfase será dada às mesorregiões em detrimento das macrorregiões. É evidente, também, o estreitamento das parcerias entre as universidades, o Estado e as empresas, modelo chamado no plano de "tríplice hélice", considerado o modelo ideal para o desenvolvimento de uma Agenda Nacional de Pesquisa com a participação de todas as agências de fomento, quer no âmbito federal ou no âmbito estadual.

Esse conjunto de orientações contidas nos vários PNPGs representa uma posição clara dos governos, inclusive de orientação política diferenciada, no sentido de reconhecer que esse nível educacional é estratégico para a produção de conhecimento, fator determinante para a inserção do país nas relações do mundo globalizado.

\section{Expansão da pós-graduação no Brasil: traços e características}

A pós-graduação se constitui em um espaço privilegiado para a formação de quadros profissionais de alto padrão de qualidade e para a produção de conhecimento, como resultado da realização de pesquisa científica em todas as áreas. Portanto, em um contexto social em que o conhecimento assume foro privilegiado, a pós-graduação se destaca como uma área de ensino estratégica para que os países se integrem de forma 
mais competitiva no cenário global. O crescimento da pós-graduação no Brasil situa-se, portanto, nesse contexto em que o país procura se inserir competitivamente no mercado mundial, em que a produção de conhecimento e sua aplicabilidade em forma de tecnologia e produtos sociais se tornam um imperativo. O quadro de expansão da pós-graduação, no país, apresentado nas páginas subsequentes deste artigo é, portanto, produto dessas novas demandas contextuais e, também, de uma política induzida pelo governo, por meio de Planos Nacionais de Pós-Graduação, com metas e estratégias para a expansão desse nível educacional.

Para fins dessa discussão sobre a ampliação da pós-graduação no Brasil, toma-se como dimensões de análise a evolução no número de cursos de pós-graduação no país, por região geográfica, e a evolução da sua matrícula.

\section{EVOLUÇÃO DO NÚMERO DE CURSOS NO PAÍS}

Nos últimos anos, pode ser observado um crescimento da pósgraduação no Brasil; no entanto esse crescimento não se dá de forma homogênea. O sistema de pós-graduação no país foi-se configurando como um sistema multifacetado, composto por programas de mestrado profissional, mestrado acadêmico e doutorado, públicos e privados, e vem se diversificando e representando diferentes papéis e funções.

Os dados sistematizados na Tabela 01 demonstram, no geral, um destacado crescimento do número de cursos de pós-graduação no país em todos os níveis, assim como uma forte desigualdade na distribuição desses cursos pelas diversas regiões geográficas.

Especificamente, no que concerne ao crescimento do número de cursos de pós-graduação, conforme dados da Tabela 01, evidencia-se que houve um aumento de 30,6\% no período 2006 a 2010, considerando os três níveis (doutorado, mestrado e mestrado profissional). Os mestrados profissionais cresceram, no período, $68,9 \%$; os mestrados acadêmicos, $26,5 \%$; e os doutorados, 30,7\%. Esses dados confirmam um acentuado crescimento dos mestrados profissionais quando comparados com os outros dois níveis de cursos de pós-graduação. O incremento dessa modalidade foi mais relevante nas regiões mais desenvolvidas do país, ficando a região Sudeste com um crescimento de 90,9\%, no período considerado, e a região Sul com crescimento de $66,7 \%$. Esse quadro pode ter sido influenciado pelos seguintes fatores: a) ser uma modalidade nova de pós-graduação criada no país; b) ter havido indução da política de governo como modalidade a ser implantada em algumas áreas; c) constituir-se em cursos de menor duração, requerendo, consequentemente, menos investimentos e menor tempo de formação; d) ter 
havido, em algumas áreas, incentivo a essa modalidade de pós-graduação, vinculada, mais diretamente, às demandas específicas do mercado.

Tabela 01 - Número de cursos segundo a região geográfica e nível de pós-graduação, por ano, no Brasil (2006-2010).

\begin{tabular}{|c|c|c|c|c|c|c|c|}
\hline Região & Nível & \multicolumn{5}{|c|}{ Ano } & $\begin{array}{l}\Delta \% \\
30,9\end{array}$ \\
\hline \multirow{4}{*}{ Centro-Oeste } & \multirow[b]{2}{*}{ Doutorado } & 2006 & 2007 & 2008 & 2009 & 2010 & \multirow{2}{*}{30,9} \\
\hline & & 68 & 72 & 76 & 78 & 89 & \\
\hline & Mestrado & 123 & 135 & 141 & 147 & 150 & 22,0 \\
\hline & Mestrado profissional & 0 & 0 & 0 & 0 & 1 & - \\
\hline \multicolumn{2}{|r|}{ Centro-oeste total } & 191 & 207 & 217 & 225 & 240 & 25,7 \\
\hline \multirow[t]{3}{*}{ Sudeste } & Doutorado & 276 & 291 & 307 & 324 & 336 & 21,7 \\
\hline & Mestrado & 402 & 423 & 458 & 485 & 514 & 27,9 \\
\hline & Mestrado profissional & 11 & 12 & 15 & 19 & 21 & 90,9 \\
\hline \multicolumn{2}{|r|}{ Sudeste total } & 689 & 726 & 780 & 828 & 871 & 26,4 \\
\hline \multirow[t]{3}{*}{ Nordeste } & Doutorado & 141 & 159 & 173 & 190 & 204 & 44,7 \\
\hline & Mestrado & 304 & 307 & 344 & 367 & 385 & 26,6 \\
\hline & Mestrado profissional & 13 & 14 & 13 & 15 & 19 & 46,2 \\
\hline \multicolumn{2}{|r|}{ Nordeste total } & 458 & 480 & 530 & 572 & 608 & 32,8 \\
\hline \multirow[t]{3}{*}{ Sul } & Doutorado & 144 & 159 & 170 & 182 & 189 & 31,3 \\
\hline & Mestrado & 227 & 246 & 261 & 269 & 283 & 24,7 \\
\hline & Mestrado profissional & 3 & 3 & 4 & 4 & 5 & 66,7 \\
\hline \multicolumn{2}{|r|}{ Sul total } & 347 & 408 & 435 & 455 & 477 & 37,5 \\
\hline \multirow[t]{3}{*}{ Norte } & Doutorado & 17 & 23 & 24 & 30 & 26 & 52,9 \\
\hline & Mestrado & 75 & 82 & 88 & 96 & 99 & 32,0 \\
\hline & Mestrado profissional & 2 & 3 & 2 & 2 & 3 & 50,0 \\
\hline \multicolumn{2}{|r|}{ Norte total } & 94 & 108 & 114 & 128 & 128 & 36,2 \\
\hline \multicolumn{2}{|r|}{ BRASIL } & 1.779 & 1.929 & 2.076 & 2.208 & 2.324 & 30,6 \\
\hline
\end{tabular}

Fonte: Planilha IFES / Andifes 2011, elaboração dos autores.

Outro aspecto que merece realce diz respeito ao fato de que o percentual de crescimento do número de doutorado é superior àquele relativo ao de mestrado. Isso pode ser explicado pelo fato de que o nível de mestrado já se encontra mais consolidado no país e que as instituições estão concentrando esforços para ampliar a pós-graduação em nível de doutorado. Decorre, também, como lembram Viotti et al (2010), do fato de que algumas atividades passaram a exigir esse patamar educacional - de docentes universitários e pesquisadores, por exemplo - como uma condição mínima de formação, para que possam atuar. Os autores lembram que, mesmo nos casos em que o doutorado não é requisito necessário para exercer a atividade 
profissional, essa titulação é extremamente valorizada nas contratações para uma crescente variedade de postos de trabalho. O próprio sistema nacional de pós-graduação, como assinalam os autores, é parte desse ambiente que valoriza os programas de doutorado, na medida que a expansão da pósgraduação gera uma demanda de profissionais - que se dedicam em tempo integral às atividades de ensino e à pesquisa - dos quais a exigência de titulação em nível de doutorado é, hoje, essencial.

Essa prevalência do doutorado pode ser, também, explicada pela necessidade de o país formar recursos humanos de alta qualificação para a sua inserção no mundo globalizado, tendo-se colocado para o Brasil um imperativo de conceber uma política nessa direção.

Segundo Viotti et al (2010), o crescimento dos cursos de pósgraduação no Brasil, nas quatro últimas décadas, decorreu da adoção de uma política consistente que permaneceu independentemente de mudanças de governos e até de regimes políticos, caracterizando-se, desse modo, como uma politica de Estado. A esse respeito, Balbachevsky afirma que os dados disponíveis

colocam a pós-graduação brasileira entre as mais importantes do mundo. Além do tamanho alcançado, a pós-graduação brasileira também impressiona pela qualidade. Desde o final dos anos 1960, nossa pós-graduação vem sendo submetida a um conjunto consistente de políticas que lhe permitiu crescer e, ao mesmo tempo, manter qualidade. (BALBACHEVSKY, 2005, p. 276)

Essa política foi delineada pelo governo brasileiro a partir da decisão da formulação de Planos Nacionais de Pós-Graduação iniciada no ano de 1975, conforme já assinalado nas páginas precedentes deste artigo. Como aspectos relevantes inscritos nesses planos, pode-se destacar: a formação de docentes e pesquisadores; a integração da pós-graduação ao sistema de Ciência e Tecnologia; a produção de conhecimento para o desenvolvimento nacional; a integração da pós-graduação com o setor empresarial e com a sociedade; a ampliação da oferta da pós-graduação como estratégia para o processo de desenvolvimento socioeconômico e cultural da sociedade; dentre outros.

Merece realce, também, no âmbito deste artigo, a natureza jurídica das instituições em que ocorre a formação dos doutores. Viotti et al (2010), analisando a evolução dos programas de pós-graduação no país, no período 1998 a 2008, evidenciam que houve um acentuado crescimento na sua oferta, tanto nas instituições públicas federais e estaduais, quanto na iniciativa privada; esse aumento, porém, ocorreu de forma muito diferenciada. 
O estudo dos referidos autores demonstra o seguinte: o número de programas, em instituições estaduais, cresceu $32 \%$ nesse período, mas teve sua participação reduzida, de 40,0\% do total em 1998, para 32,0\% em 2008. O quantitativo de programas de doutorado vinculados a instituições federais aumentou $88,0 \%$ no período, tendo passado sua participação relativa no total de $51,0 \%$ para $57,0 \%$. O número de programas de doutorado vinculados a instituições privadas apresentou uma elevação de 123,0\% no período, e sua participação relativa passou, de 8,4\% em 1998, para 11,2\% no ano de 2008 .

Esse crescimento verificado na iniciativa privada foi acentuado nos últimos anos e representa uma participação crescente dessas instituições na formação de doutores. Entretanto, cabe ressalvar que esses programas de instituições privadas também recebem forte apoio das agências públicas federais e estaduais de fomento à Ciência e Tecnologia. O seu crescimento, como destacam Viotti et al (2010), ocorreu, majoritariamente, nas áreas das Ciências Sociais Aplicadas e das Ciências Humanas que, no ano de 2008, concentram respectivamente $35,2 \%$ e $21,5 \%$ dos programas de doutorado existentes no país. Uma das explicações para tal situação pode ser, ainda na interpretação de Viotti et al (2010), o baixo investimento - relativamente, em infraestrutura física e laboratorial - requerido pelos programas de doutorado nessas áreas. Em relação à pós-graduação, constata-se, nesse momento, que esse nível educacional passa a ser alvo de investimento do empresariado, na mediada que se constitui em um campo propício para a valorização do capital, tendência essa já consolidada na graduação brasileira que abarca mais de $70 \%$ das matrículas.

Como se pode constatar pelos dados apresentados, cada vez mais, o governo federal vem assumindo papel importante na formação de doutores no país - tanto pela sua ampliação na oferta de cursos, quanto pelo aumento de apoio financeiro às instituições estaduais e particulares -, mediante o financiamento de projetos de pesquisa e de bolsas de estudos. Além disso, o governo federal consolidou uma política de regulação e avaliação que tem garantido planos crescentes de qualidade a esse nível de educação.

Em relação à distribuição dos cursos de pós-graduação no território brasileiro, observa-se, conforme dados da Tabela 01, uma forte concentração desses cursos na região Sudeste, embora, nos últimos anos, esteja em desenvolvimento um significativo processo de desconcentração de programas pelas demais regiões do país. Do total de cursos de pós-graduação existentes no país em 2006, 38,7\% se localizavam em instituições situadas na região Sudeste; $25,8 \%$, na região Nordeste; 19,5 , na região Sul; $10,7 \%$, na região Centro-Oeste; e 5,3\%, na região Norte. Comparando-se esses dados de 2006 
com aqueles existentes em 2010, constata-se que vem ocorrendo, ainda que de forma lenta, uma reconfiguração no quadro da distribuição de cursos de pós-graduação no Brasil. Em 2010, percebe-se que o Nordeste passa a deter 26,2\% dos cursos de pós-graduação e a Região Sul, 21,0\%, o que representa um aumento da participação dessas duas regiões na composição geral dos cursos no país. Nesse mesmo ano de 2010, verifica-se uma menor participação da região Sudeste que passa a deter 37,55 do total de cursos, representando uma menor participação do que aquela verificada em 2006 (38,7\%).

O recorte nos dados relativos ao quadro dos cursos de doutorado, sistematizados na Tabela 01, permite maior visibilidade sobre o processo de desconcentração desse nível formativo em curso no Brasil. No período de 2006 a 2010, a taxa de crescimento de cursos de doutorado é ilustrativa desse processo de desconcentração. Enquanto a região Sudeste cresceu, apenas, 21,7\%, as regiões Norte e Nordeste cresceram, respectivamente, $52,9 \%$ e $44,7 \%$. Também o aumento no número de cursos verificado nas regiões Centro-Oeste (30,9\%) e Sul (32,3\%) é superior ao constatado na região Sudeste. Essa situação deve-se ao fato de que a região Sudeste possui, historicamente, uma maior inserção nesse nível educacional e, portanto, é lógico que, nela, ocorra uma desaceleração do seu crescimento.

Esse processo de desconcentração regional na formação de doutores significa que as regiões menos desenvolvidas estão, cada vez mais, investindo na qualificação de profissionais de alto nível, o que poderá resultar em sua inserção no cenário nacional em melhores condições de competitividade em todos os campos. É preciso realçar que esse processo vem ocorrendo com base em uma política do governo federal que tem desenvolvido ações diferenciadas para corrigir distorções históricas entre as regiões do país. Particularmente no VI PNPG (2010-2020), há uma nítida referência à necessidade de combate às assimetrias regionais, reafirmando que essa temática é de grande complexidade e, portanto, exigirá uma ação sinérgica de vários órgãos de governo; ao mesmo tempo, indica que a ênfase das ações será dada às mesorregiões em detrimento das macrorregiões. Não obstante a constatação de uma tendência de redução das assimetrias regionais, observase que a região Sudeste ainda detém hegemonia nesse campo, visto que sedia 871 cursos de doutorado dos 2.324 existentes em 2010 no país.

\section{EXPANSÃO NA MATRÍCULA}

O Brasil, nos últimos anos, como parte de sua política, conforme analisado na seção anterior deste artigo, vem ampliando a oferta de cursos de pós-graduação em todos os níveis. Esse aumento do número de cursos 
representou também um incremento significativo na matrícula na pósgraduação stricto sensu. Os dados sistematizados na Tabela 2, apresentada a seguir, permitem visualizar como esse fenômeno vem ocorrendo nos últimos 10 anos no país.

Tabela 2 - Evolução do número de matrículas na pós-graduação no Brasil, por nível (2001-2011)

\begin{tabular}{|c|c|c|c|c|c|c|c|}
\hline Ano & Total & Mestrado & $\%$ & Doutorado & $\%$ & $\begin{array}{c}\text { Mestrado } \\
\text { profissionalizante }\end{array}$ & $\%$ \\
\hline $\mathbf{2 0 0 1}$ & $\mathbf{1 0 0 . 4 4 3}$ & 62.353 & 62,1 & 35.134 & 35,0 & 2.956 & 2,9 \\
\hline $\mathbf{2 0 0 2}$ & $\mathbf{1 0 6 . 0 6 8}$ & 63.990 & 60,3 & 37.728 & 35,6 & 4.350 & 4,1 \\
\hline $\mathbf{2 0 0 3}$ & $\mathbf{1 1 2 . 2 2 9}$ & 66.951 & 59,7 & 40.213 & 35,8 & 5.065 & 4,5 \\
\hline $\mathbf{2 0 0 4}$ & $\mathbf{1 1 6 . 2 6 0}$ & 69.190 & 59,5 & 41.261 & 35,5 & 5.809 & 5,0 \\
\hline $\mathbf{2 0 0 5}$ & $\mathbf{1 2 4 . 0 4 8}$ & 73.805 & 59,5 & 43.942 & 35,4 & 6.301 & 5,1 \\
\hline $\mathbf{2 0 0 6}$ & $\mathbf{1 3 2 . 4 2 0}$ & 79.050 & 59,7 & 46.572 & 35,2 & 6.798 & 5,1 \\
\hline $\mathbf{2 0 0 7}$ & $\mathbf{1 4 1 . 6 6 1}$ & 84.356 & 59,5 & 49.667 & 35,1 & 7.638 & 5,4 \\
\hline $\mathbf{2 0 0 8}$ & $\mathbf{1 5 0 . 1 1 8}$ & 88.295 & 58,8 & 52.750 & 35,1 & 9.073 & 6,0 \\
\hline $\mathbf{2 0 0 9}$ & $\mathbf{1 6 1 . 0 6 8}$ & 93.016 & 57,7 & 57.917 & 36,0 & 10.135 & 6,3 \\
\hline $\mathbf{2 0 1 0}$ & $\mathbf{1 7 3 . 4 0 8}$ & 98.607 & 56,9 & 64.588 & 37,2 & 10.213 & 5,9 \\
\hline $\mathbf{2 0 1 1}$ & $\mathbf{1 8 7 . 7 6 0}$ & 104.178 & 55,5 & 71.387 & 38,0 & 12.195 & 6,5 \\
\hline $\mathbf{2 0 0 1 / 2 0 1 1}$ & $\mathbf{8 6 , 9}$ & $\mathbf{6 7 , 1}$ & - & $\mathbf{1 0 3 , 2}$ & - & $\mathbf{3 1 2 , 6}$ & - \\
\hline$\Delta \%$ & & & & & & & \\
\hline
\end{tabular}

Os dados da Tabela 2 permitem evidenciar um quadro de significativa expansão na matrícula nesse nível educacional nos últimos 10 anos, em todas as modalidades de curso. $O$ crescimento global da matrícula na pós-graduação do período foi de $86,9 \%$; entretanto esse crescimento vem se acentuando a partir do ano de 2008. A expansão entre os anos de 2008 e 2009 foi de 7,3\%; entre os anos 2009 e 2010 foi de 7,7\%; e entre 2010 e 2011 atingiu os $8,3 \%$. Esses percentuais de matrícula são superiores aos verificados nos anos anteriores, cujos índices variam entre 3,6\% e 7,0\%.

Tomando-se os níveis de pós-graduação (doutorado, mestrado acadêmico e mestrado profissional), constata-se que a ampliação da matrícula ocorreu em todos eles. $\mathrm{O}$ crescimento em nível de mestrado acadêmico foi menor $(67,1 \%)$ do que nos níveis de doutorado e mestrado, ficando abaixo da média global (86,9\%). O aumento da matrícula em nível de doutorado ficou em $103,2 \%$, significando que houve mais do que uma duplicação do número de alunos matriculados em cursos de doutorado. $O$ menor crescimento da matrícula, observado em relação ao nível de mestrado no período em análise, pode ser decorrente do fato de que o país já tivesse, em uma primeira fase de implantação da pós-graduação, atingido mais amplamente essa modalidade 
de cursos. O maior crescimento dos cursos de doutorado decorre não apenas de novas iniciativas de políticas governamentais, mas também do fato de que muitas instituições de ensino superior já haviam consolidado os seus cursos de mestrado e passaram a reorganizar a pós-graduação em forma de programas, incluindo o mestrado e o doutorado.

O maior crescimento da matrícula na pós-graduação, nesse período, se deu na modalidade de mestrado profissional que atingiu o patamar de $312,6 \%$. Esse crescimento foi induzido pelas políticas governamentais, principalmente, na busca de organizar cursos de menor duração, voltados, sobretudo, para as áreas específicas e vinculados às demandas do mercado.

Embora se tenha constatado um aumento maior da matrícula nos níveis de doutorado e mestrado profissional, quando se observa a composição geral da matrícula na pós-graduação, evidencia-se que é no mestrado que, ainda, se concentra o maior percentual de matrículas. No ano de 2011, dos 187.760 alunos da pós-graduação no Brasil, 55,5\% estavam matriculados em cursos de mestrado; 38,0\% em cursos de doutorado; e 6,5 \% em cursos de mestrado profissional. Todavia, os dados relativos ao período 2001-2011 demonstram que esse nível da pós-graduação vem perdendo importância na composição geral da matrícula. No ano de 2001, o mestrado tinha 62,1\% das matrículas; o doutorado, 35,0\%; e o mestrado profissional, 2,9\%.

Esse aumento na matrícula, na pós-graduação, resultou, por sua vez, na maior titulação de profissionais qualificados para atuar em todas as áreas de conhecimento. Especificamente no que se refere à titulação de doutor - formação exigida para o exercício profissional em várias ocupações e indispensável para o exercício da pesquisa -, verifica-se um crescimento marcado por uma tendência de desconcentração regional. Em 1996, foram titulados, no Brasil, 2.830 doutores e, em 2008, 10.705, o que representa um aumento de $278,3 \%$ no número de concluintes nesse nível educacional (Coleta Capes/VIOTTI et al, 2010).

Nesse crescimento, observa-se que vem se materializando um processo contínuo de desconcentração do número de titulados no país. Os dados sistematizados por Viotti et al (2010), a partir de dados da Coleta Capes, informam que, em 1969, o grau de concentração era muito maior do que o verificado em 2008. Em 1996, as instituições situadas no Sudeste titularam 88,9\% do total de doutores no Brasil; em 2008, essa região reduziu significativamente a sua participação na titulação de doutores, formando, apenas, $70,1 \%$.

Esse declínio relativo à região Sudeste na titulação de doutores foi motivado, dentre outros fatores, pelo crescimento mais acelerado desse 
fenômeno nas demais regiões do país. Enquanto o número de titulados na região Sudeste cresceu $198 \%$ durante o período, na região Norte cresceu 438\%; na região Sul, 682,\%; na Centro-Oeste, $840 \%$; e na região Nordeste, $2.487 \%$. Essa última região, por exemplo, teve a sua participação aumentada de 1,4\%, em 1996, para 10,0\%, em 2008, no total de titulados no país (Coleta Capes/VIOTTI el al, 2010).

Embora se constate, a partir dos dados aqui apresentados, que no Brasil, nos últimos anos, vem se investindo na formação de quadros com a titulação de doutor, a proporção dos profissionais titulados em relação ao tamanho da população apresenta-se, ainda, muito inferior àquela verificada nos países mais desenvolvidos. Segundo Viotti et al (2010), no ano de 2008, no Brasil, o número de doutores correspondia a, apenas, 0,07 da população global e a 0,14\% da população na faixa etária entre 25 e 64 anos de idade. Na Suíça, na Alemanha e nos Estados Unidos, em 2003, os índices para a faixa etária de 25 a 64 eram, respectivamente, de 23,0\%, 15,4\% e 8,4\%.

Com esse quadro, como assinalam Viotti et al (2010), caso o Brasil queira contar, em seu esforço de desenvolvimento, com doutores em proporções similares às de países desenvolvidos, ainda será necessário multiplicar por 4,5 ou mais vezes a participação de doutores em sua população.

Diante de tal situação, o Brasil necessita ainda realizar vultosos investimentos na formação de doutores, considerando que eles são os profissionais que, de modo geral, têm papel preponderante na produção do conhecimento científico e no desenvolvimento de novas tecnologias, aspectos necessários para que o país se insira de forma mais competitiva na economia global e informacional.

\section{CONSIDERAÇÕES FINAIS}

Nos últimos anos, ocorre uma intensificação do processo de globalização em todas as áreas. Consolida-se uma arquitetura social fundada em uma lógica na qual os processos econômicos estão articulados mundialmente, a partir de interesses de agentes globais de desenvolvimento. Há, sem dúvida, uma economia globalizada e internacional que vem afetando todas as nações; entretanto é evidente que a forma como os países se inserem nesse movimento é diferenciada. A articulação dos países na economia globalizada está ligada com a posição econômica e política que ocupam no cenário mundial. Cada vez mais, fica patente que a força que as nações têm nesse momento está relacionada, dentre outros fatores, com a sua capacidade de investimento em ciência e tecnologia. Para imprimir concretude a esse movimento, tornam-se 
necessários investimentos em recursos humanos de alta qualificação, papel destinado, predominantemente, aos cursos de pós-graduação.

A pós-graduação, nesse contexto de globalização, assume importância fulcral. Ela passa a ser um dos espaços privilegiados e estratégicos de formação de pesquisadores/cientistas que têm função essencial na produção de conhecimentos e no desenvolvimento de novas tecnologias. Nesse sentido, assiste-se a uma tendência de os países investirem mais nesse nível educacional e, por isso, ocorre uma efetiva ampliação de cursos de pós-graduação.

O Brasil, nas últimas décadas, se insere nessa dinâmica e vem ampliando os cursos de pós-graduação e sua consequente matrícula, assim como o número de titulados, expandindo, dessa forma, o seu quadro de pesquisadores. Dentre as principais conclusões a que se pode chegar para a situação brasileira, no período analisado, são evidentes: a) um reconhecido crescimento, no país, do número de cursos de pós-graduação e da matrícula em todos os níveis; b) uma expressiva desigualdade na distribuição desses cursos e de sua matrícula pelas diversas regiões geográficas, embora esteja em curso uma leve tendência de alteração desse quadro, visto que as regiões menos desenvolvidas vêm aumentando gradativamente a sua participação no quadro geral dos cursos e das matrículas; c) mesmo com esse movimento de desconcentração regional, verifica-se que o Sudeste, no ano de 2010, concentrava, ainda, $66,8 \%$ dos cursos de pós-graduação, embora, nos últimos dez anos, tenha crescido menos do que as demais regiões do país; d) o crescimento da pós-graduação vem se efetivando, no Brasil, nas últimas décadas, em decorrência de uma política formulada em Planos Nacionais de Pós-Graduação que destacam a importância desse nível educacional para o seu desenvolvimento socioeconômico e cultural; e) a adoção, pelo governo, de estratégias de indução do crescimento, gerado por uma política de financiamento para esse nível educacional.

Por fim, destaca-se que o crescimento da pós-graduação, no país, não significa que ele esteja em uma posição confortável, quando sua realidade é comparada à de outros países (Alemanha, Suécia, Estados Unidos, por exemplo), no que concerne à relação entre o número de doutores e a sua população na faixa de 25 a 64 anos de idade. O Brasil, para chegar ao patamar desses países, necessitaria, como foi dito, de, pelo menos, multiplicar por quatro e meio ou mais vezes a participação de doutores em sua população. Nesse sentido, o Brasil necessita realizar, ainda, investimentos significativos na formação de doutores para que construa caminhos mais promissores para a sua inserção qualificada e, portanto, mais competitiva no mundo globalizado. A falta desses investimentos colocará o país sempre em posição subordinada 
nessa dinâmica em que países que produzem mais conhecimento e tecnologia assumem posição hegemônica.

\section{THE EXPANSION OF GRADUARE EDUCATION AGAINST A BACKGROUND OF GLOBALIZATION: SNIPPETS OF THE BRAZILIAN SITUATION}

ABSTRACT:The paper analyzes the process of globalization in the context of technological innovation and its repercussions on education. It discusses the centrality of the production of knowledge for the competitiveness of nations and the role played by graduate education as the privileged locus for producing it. It analyzes the expansion of this educational level, in Brazil, in recent decades, based on data from GeoCapes. In the present context of globalization, it concludes that graduate education is of crucial importance in that it is a privileged strategic space for the formation of researchers who play a vital role in the production of knowledge and development of new technologies. In Brazil the number of research personnel has increased as seen from the expansion in the number of courses, enrollments and graduate students.

Keywords: Globalization. Graduate Education. Knowledge production.

\section{LA EXPANSIÓN DEL POSGRADO EN ESCENARIOS DE GLOBALIZACIÓN: RECORTES DE LA SITUACIÓN BRASILEÑA}

Resumen: El artículo analiza el proceso de globalización en el contexto de las innovaciones tecnológicas y las repercusiones en el campo de la educación. Discute la centralidad de la producción del conocimiento para la competitividad de las naciones y el papel que el posgrado exerce como lócus privilegiado de su producción. Analiza la expansión de ese nivel educacional, en el Brasil, en las últimas décadas, basándose en los datos del GeoCapes. Se concluye que el posgrado, en ese contexto de globalización, asume importancia crucial, constituyéndose en un espacio privilegiado y estratégico de formación de investigadores que desempeñan papel base en la producción de conocimientos y en el desarrollo de nuevas tecnologías. En ese contexto, el Brasil ha ampliado su cuadro de investigadores, lo que puede constatarse por la expansión de los cursos, de las matrículas y del número de titulados.

Palabras Claves: Globalización. Posgrado. Producción del conocimiento.

\section{REFERÊNCIAS}

BALBACHEVSKY, E. A pós-graduação no Brasil: novos desafios para uma política bem-sucedida. In:BROCK, C.; SCHWARTZMAN, S. (Org.). Os desafios da educação no Brasil. Rio de Janeiro: Nova Fronteira, 2005, p. 275-304. Disponível em: http://www.schwartzman. org.br/simon/desafi os/9posgrado.pdf. Acesso em: 30 set. 2012.

BARBALHO, M. G. C.; CASTRO, A. M. D. A. Globalização e educação superior: discutindo tendências de internacionalização. In: CABRAL NETO, A.; REBELO, M. P. P. V. (Org.). O 
ensino superior no Brasil e em Portugal: perspectivas políticas e pedagógicas. Natal: EDUFRN, 2010. p. 47-72.

BRASIL. Ministério da Educação e Cultura, Secretaria de Educação Superior/ Coordenação de Aperfeiçoamento de Pessoal de Nível Superior I Plano Nacional de Pós-Graduação: 1975-1979. Brasília: MEC/SESU/CAPES, 1975.

BRASIL. II Plano Nacional de Pós-Graduação: 1982-1985. Brasília: MEC/SESU/CAPES, 1982.

BRASILIII Plano Nacional de Pós-Graduação: 1986-1989. Brasília: MEC/SESU/CAPES, 1986.

BRASIL. V Plano Nacional de Pós-Graduação: 2005-2010. Brasília: MEC/CAPES, 2004.

BRASIL. VI Plano Nacional de Pós-Graduação: 2005-2010. Brasília: MEC/CAPES, 2005.

BRASIL. Ministério da Educação. Fundação Coordenação de Aperfeiçoamento de Pessoal de Nível Superior. História e missão. Brasília, MEC/CAPES, 2010. Disponível em: http://www.capes.gov.br/sobre-a-capes/historia-e-missao. Acesso em: 06 ago. 2012.

CARNOY, M. El ajuste estructural y la evolución del mundo de la enseñanza. Revista Internacional del Trabajo, Genebra, v. 114, n. 6, p. 727-752, 1995.

CARNOY, M. Mundialização e reforma da educação: o que os planejadores devem saber. Trad. Guilherme J. de Freitas Teixeira. Brasília: Unesco, 2002.

CASTELLS, M. A sociedade em rede. Trad. Roneide Venâncio Majer. São Paulo: Paz e Terra, 2001.

CONSELHO FEDERAL DE EDUCAÇÃO. COMISSÃO DE EDUCAÇÃO SUPERIOR. Parecer n. 977/65 (aprovado em 3 de dezembro de 1965).

FAINHOLC, B. Los nuevos escenarios de la educación superior internacional y su problemática actual. 2005. Disponível em: www.iesalc.unesco.org.ve. Acesso em: 23 jun. 2012.

JAMESON, F. A cultura do dinheiro: ensaios sobre globalização. Petrópolis:Vozes, 2001.

JANTSCH, A. P. Mercadorização, formação, universidade pública e pesquisa crítico-emancipatória: em tempo de realização plena do conceito de capital. In: OLIVEIRA, J. F. de; CATANI, A. M.; SILVA JÚNIOR, J. R. (Org.). Educação superior no Brasil: tempos de internacionalização. São Paulo: Xamã, 2010. p. 55-78.

MANCEBO, D. Reflexões sobre a pós-graduação no Brasil: novos rumos e pragmatismo como fundamento. In: CHAVES, V. L. J.; SILVA JÚNIOR, J. R. (Org.). Educação superior no Brasil e diversidade regional. Belém: EDUFPA, 2008. p. 171-187.

MELLO, A. F. Globalização, sociedade do conhecimento e educação superior: os sinais de Bolonha e os desafios do Brasil e da América Latina. Brasília: Unb, 2011.

OLIVEN, A. C. Histórico da educação superior no Brasil. In: SOARES, M. S. A. (Org.). A educação superior no Brasil. Brasília: Coordenação de Aperfeiçoamento de Pessoal de Nível Superior, 2002. p. 31- 42. 
PORTUGAL. Ministério da Ciência, Tecnologia e Ensino Superior. Processo de Bolonha. 1999. Disponível em: http://www.dges.mctes.pt/DGES/pt/Estudantes/ Processo+de+Bolonha/Processo+de+Bolonha/. Acesso em: 20 set. 2012.

SANTOS, A. L. F. dos. A pós-graduação em educação e o tratamento do tema política educacional: uma análise da produção do conhecimento no nordeste do Brasil. Recife: Editora Universitária da UFPE, 2009.

TEIXEIRA, A. S. Ensino superior no Brasil: análise e interpretação de sua evolução até 1969. Rio de Janeiro: Editora da UFRJ, 2005. v. 10.

UNESCO. Conferência Regional de Educação Superior (CRES). 2008. Disponível em: http://www.interlegis.gov.br. Acesso 26 set. 2012.

VIOTTI, E. B. et al. Doutorados e doutores titulados no Brasil: 1996-2008. In: Doutores 2010: estudos da demografia da base técnico-científica brasileira. Brasília: Centro de Gestão e Estudos Estratégicos, 2010. p. 49-105.

ANTÔNIO CABRAL NETO: doutor em Educação pela Universidade de São Paulo e professor do Programa de Pós-Graduação em Educação da Universidade Federal do Rio Grande do Norte.

E-mail: cabraln@ufrnet.br.

ALDA MARIA DUARTE ARAÚJO CASTRO: doutora em Educação pela Universidade Federal do Rio Grande do Norte, com pós-doutorado na Universidade de Coimbra/Portugal e professora do Programa de Pós-Graduação em Educação da Universidade Federal do Rio Grande do Norte.

E-mail:alda@urrnet.br. 